\title{
The Use of D-Optimal Mixture Design in Optimizing Development of Okara Tablet Formulation as a Dietary Supplement
}

\author{
Nur Izzati Mohamad Zen, ${ }^{1}$ Siti Salwa Abd Gani, ${ }^{1,2,3}$ \\ Rosnah Shamsudin, ${ }^{4}$ and Hamid Reza Fard Masoumi ${ }^{3}$ \\ ${ }^{1}$ Halal Product Research Institute, Universiti Putra Malaysia (UPM), 43400 Serdang, Selangor, Malaysia \\ ${ }^{2}$ Centre of Foundation Studies for Agriculture Science, Universiti Putra Malaysia (UPM), 43400 Serdang, Selangor, Malaysia \\ ${ }^{3}$ Department of Chemistry, Faculty of Science, Universiti Putra Malaysia (UPM), 43400 Serdang, Selangor, Malaysia \\ ${ }^{4}$ Department of Process and Food Engineering, Faculty of Engineering, Universiti Putra Malaysia (UPM), \\ 43400 Serdang, Selangor, Malaysia
}

Correspondence should be addressed to Siti Salwa Abd Gani; ssalwa.abdgani@gmail.com

Received 20 January 2015; Revised 28 May 2015; Accepted 1 June 2015

Academic Editor: Pao-Chu Wu

Copyright (C) 2015 Nur Izzati Mohamad Zen et al. This is an open access article distributed under the Creative Commons Attribution License, which permits unrestricted use, distribution, and reproduction in any medium, provided the original work is properly cited.

\begin{abstract}
The usage of soy is increasing year by year. It increases the problem of financial crisis due to the limited sources of soybeans. Therefore, production of oral tablets containing the nutritious leftover of soymilk production, called okara, as the main ingredient was investigated. The okara tablets were produced using the direct compression method. The percentage of okara, guar gum, microcrystalline cellulose (Avicel PH-101), and maltodextrin influenced tablets' hardness and friability which are analyzed using a D-optimal mixture design. Composition of Avicel PH-101 had positive effects for both hardness and friability tests of the tablets. Maltodextrin and okara composition had a significant positive effect on tablets' hardness, but not on percentage of friability of tablets. However, guar gum had a negative effect on both physical tests. The optimum tablet formulation was obtained: $47.0 \%$ of okara, $2.0 \%$ of guar gum, $35.0 \%$ of Avicel PH-101, and $14.0 \%$ of maltodextrin.
\end{abstract}

\section{Introduction}

Okara is the by-product of the soybean milk and tofu production. The main component of okara is fiber (about $50 \%$ ) which is composed of cellulose, hemicellulose, and lignin. Okara also contains about $25 \%$ protein, $10 \%$ oil, and low amounts of starch and simple carbohydrates. Okara is also known as low-cost nutrient rich fibers in soybean [1]. According to Bowles and Demiate [2], one-third of the total amount of isoflavones remains in okara. Isoflavones have many advantages for health such as acting as an antioxidant and preventing chronic diseases like cancer and heart disease [2]. Obesity is strongly related to other chronic diseases like cardiovascular diseases and diabetes [3]. One of the methods that can manage and prevent an obesity problem is the usage of fiber-rich foods due to providing high fiber food intake satiety [4]. Hence, okara could be very effective as a dietary supplement.

There are many forms of dietary supplements, for example, tablets, capsules, liquids, powders, and gels. Dietary supplements are different from drugs, and they are nonpotent drugs. The Food and Drug Administration (FDA) defined a dietary supplement as an alternative food containing essential nutrients like vitamins, minerals, and proteins. Subsequently, the Nutrition Labeling and Education Act of 1990 added "herb or nutritional substances" to the definition. In the pharmaceutical industry, tablets are the most acceptable form for consumers in comparison with other oral dosage forms [5]. Tablet oral dosage has many advantages such as its ease of handling, chemical and physical stability, and portability. Furthermore, this type of dosage form ensures accuracy and consistency of dosages [6]. There are many examinations that 
can be done in order to maintain the physical qualities of the tablets, for example, hardness test, percentage of friability test, disintegration test, and dissolution test [7].

Tablets are mixtures of active ingredients and other excipients. Mixtures mean the sum of all the ingredients is $100 \%$ [8]. There are many types of excipient with their own function in dosage formulation: diluents or fillers, binders, lubricants, glidants, antiadherents, disintegrants, colorants, and flavor or sweeteners. The mixture design statistical method is the most suitable method used in optimizing the tablet production process. The mixture design method is usually used in mixture formulation [9]. For example, in three components of formulation,

$$
\begin{aligned}
\text { where } i & =1,2,3 \quad 0 \leq x_{i} \leq 1, \\
x_{1}+x_{2}+x_{3} & =1 .
\end{aligned}
$$

There are many types of mixture design: simplex-lattice design, simplex-centroid design, axial design, and D-optimal design. In this study, computed-generated D-optimal mixture design was used. D-optimal design is constructed to minimize the overall variance of the predicted regression coefficient by maximizing the value of determinant of the information matrix [10]. The benefits of D-optimal configuration, the experimental region is not simplex but it is irregular [11]. As compared with other designs, D-optimal design has a smaller number of runs and thus needs low cost of experimentation. Furthermore, combined mixture and process variables can be used in the same experimental design [8].

In this present work, okara and other excipients used in tablet production were optimized using D-optimal mixture design in order to meet the physical properties of the tablet in terms of hardness and friability.

\section{Materials and Methods}

\subsection{Materials}

2.1.1. Freeze-Dried Okara. A sample of okara was taken from a soymilk vendor in Serdang, Selangor, Malaysia. Prior to freeze drying of the okara, it was prefrozen at $-20^{\circ} \mathrm{C}$. The okara was then freeze-dried at $-105^{\circ} \mathrm{C}$ for 120 hours.

2.1.2. Excipients. The excipients were maltodextrin (R\&M, UK), silicon dioxide (Merck, Germany), guar gum (R\&M, UK), and Avicel PH-101 microcrystalline cellulose (FMC International, Philadelphia, PA).

\subsection{Methods}

2.2.1. Preliminary Study of Screening the Variables. Preliminary study on tablet formulation was done by investigating the ingredients in tablet. Four excipients were chosen for okara tablet formulation based on their function. Three of them and okara were used as variables in D-optimal mixture design as they may have effect on the responses. The ranges
TABLE 1: Parameters studied in physical optimization of okara tablet.

\begin{tabular}{lccc}
\hline Code & Parameters & Low level & High level \\
\hline$A$ & Percentage of okara & 25 & 50 \\
$B$ & Percentage of maltodextrin & 5 & 15 \\
$C$ & Percentage of guar gum & 0 & 20 \\
$D$ & Percentage of Avicel PH-101 & 18 & 68 \\
\hline
\end{tabular}

TABLE 2: Percentage composition of okara tablet (100\%).

\begin{tabular}{lccccc}
\hline Ingredients & $A$ & $B$ & $C$ & $D$ & Silicon dioxide \\
\hline F1 & 25.05 & 15.00 & 0.00 & 57.95 & 2.000 \\
F2 & 49.97 & 15.00 & 0.81 & 32.21 & 2.000 \\
F3 & 50.00 & 5.39 & 7.05 & 35.56 & 2.000 \\
F4 & 25.02 & 5.00 & 0.00 & 67.98 & 2.000 \\
F5 & 25.00 & 8.94 & 15.22 & 48.84 & 2.000 \\
F6 & 38.02 & 5.34 & 20.00 & 34.64 & 2.000 \\
F7 & 40.21 & 9.20 & 0.00 & 48.58 & 2.000 \\
F8 & 50.00 & 9.86 & 19.98 & 18.16 & 2.000 \\
F9 & 26.01 & 14.99 & 20.00 & 37.00 & 2.000 \\
F10 & 36.95 & 15.00 & 10.50 & 35.55 & 2.000 \\
F11 & 36.53 & 5.00 & 11.57 & 44.91 & 2.000 \\
F12 & 26.73 & 5.14 & 7.88 & 58.26 & 2.000 \\
F13 & 45.52 & 11.65 & 13.27 & 27.55 & 2.000 \\
F14 & 30.61 & 15.00 & 5.76 & 46.63 & 2.000 \\
F15 & 43.06 & 11.60 & 3.80 & 39.55 & 2.000 \\
F16 & 49.97 & 15.00 & 0.81 & 32.21 & 2.000 \\
F17 & 50.00 & 5.39 & 7.05 & 35.56 & 2.000 \\
F18 & 26.01 & 14.99 & 20.00 & 37.00 & 2.000 \\
F19 & 25.05 & 15.00 & 0.00 & 57.95 & 2.000 \\
F20 & 25.02 & 5.00 & 0.00 & 67.98 & 2.000 \\
\hline & & & & &
\end{tabular}

of variables were also studied by using $\mathrm{D}$-optimal mixture design software.

2.2.2. Preparation of Okara Tablets Using D-Optimal Mixture Design. Parameters ranges for D-optimal mixture design in preparing okara tablets were prepared using Design-Expert Version 7.0 software as shown in Table 1. Okara tablet contains okara and four excipients: maltodextrin, guar gum, Avicel $\mathrm{PH}-101$, and silicon dioxide. Four independent factors were studied: amount of okara $(A)$, amount of guar gum $(B)$, amount of maltodextrin $(C)$, and amount of Avicel $\mathrm{PH}$ $101(D)$. Also, two responses were examined: hardness and percentage of friability. These four variables generated 20 formulations of okara tablet with different composition of each ingredient as shown in Table 2.

2.2.3. Tableting Using Direct Compression Method. The composition of okara, guar gum, Avicel PH-101, and maltodextrin was prepared according to data prepared by Design-Expert Version 7.0 software, while the composition of silicon dioxide was constant and they were mixed using the Glas-Col Dry Powder Rocking Shaker (Glas-Col, LLC, Terre Haute, IN, USA). The tableting processes were done with compression 
TABLE 3: Actual and predicted values for hardness and friability of okara tablet formulation.

\begin{tabular}{|c|c|c|c|c|c|c|}
\hline Ingredients & $\begin{array}{l}\text { Actual hardness } \\
\qquad(\mathrm{kN})\end{array}$ & $\begin{array}{l}\text { Predicted hardness } \\
\qquad(\mathrm{kN})\end{array}$ & $\begin{array}{c}\text { Hardness } \\
\text { RSE } \\
(\%)\end{array}$ & $\begin{array}{c}\text { Actual friability } \\
(\%)\end{array}$ & $\begin{array}{l}\text { Predicted friability } \\
(\%)\end{array}$ & $\begin{array}{c}\text { Friability } \\
\text { RSE } \\
(\%)\end{array}$ \\
\hline $\mathrm{F} 1$ & 116.84 & 116.96 & 0.1017 & 1.342 & 1.147 & 16.9891 \\
\hline F2 & 83.78 & 84.01 & 0.2697 & 1.731 & 1.730 & 0.0602 \\
\hline F3 & 68.37 & 70.75 & 3.3625 & 1.896 & 1.957 & 3.1653 \\
\hline $\mathrm{F} 4$ & 124.25 & 120.81 & 2.8433 & 0.940 & 0.968 & 2.7952 \\
\hline F5 & 73.88 & 78.13 & 5.4446 & 1.229 & 2.012 & 38.8902 \\
\hline F6 & 48.45 & 50.49 & 4.0368 & 2.382 & 2.53023 & 5.8732 \\
\hline F7 & 83.73 & 100.46 & 16.6572 & 1.236 & 1.366 & 9.5770 \\
\hline F8 & 39.16 & 34.03 & 15.0890 & 3.268 & 2.865 & 14.0424 \\
\hline F9 & 60.25 & 61.64 & 2.2494 & 2.600 & 2.447 & 6.2418 \\
\hline F10 & 71.84 & 73.85 & 2.7251 & 1.670 & 2.073 & 19.4233 \\
\hline F11 & 46.28 & 75.28 & 38.5186 & 2.179 & 1.953 & 11.5650 \\
\hline $\mathrm{F} 12$ & 84.65 & 97.32 & 13.0164 & 1.310 & 1.511 & 13.2689 \\
\hline F13 & 31.74 & 57.04 & 44.3645 & 2.044 & 2.373 & 13.8413 \\
\hline F14 & 97.88 & 94.50 & 3.5751 & 1.671 & 1.635 & 2.1961 \\
\hline F15 & 81.81 & 85.76 & 4.6016 & 1.755 & 1.713 & 2.4478 \\
\hline F16 & 83.78 & 84.01 & 0.2697 & 1.878 & 1.730 & 8.5422 \\
\hline F17 & 72.52 & 70.75 & 2.5033 & 1.881 & 1.957 & 3.9171 \\
\hline F18 & 64.24 & 61.64 & 4.2255 & 2.295 & 2.447 & 6.2346 \\
\hline F19 & 116.84 & 116.96 & 0.1017 & 1.229 & 1.147 & 7.0760 \\
\hline F20 & 121.21 & 120.81 & 0.3319 & 1.064 & 0.968 & 10.0074 \\
\hline
\end{tabular}

using the Instron 5566 (Instron Corporation, Norwood, MA, USA) at 9.8 kilonewtons $(\mathrm{kN})$ with a velocity of $0.01 \mathrm{~mm} / \mathrm{s}$.

\subsubsection{Physical Evaluation of Tablets}

(1) Hardness of Okara Tablets. Hardness or crushing strength of the tablets was measured using the Instron 5566 (Instron Corporation, Norwood, MA, USA) in diametric compression with a velocity of $0.016 \mathrm{~mm} / \mathrm{s}$. Hardness was expressed in kilonewton $(\mathrm{kN})$.

(2) Friability of Okara Tablets. Friability of the tablets was evaluated using the Friabilator DF-3 (Distek Incorporation, North Brunswick, NJ, USA) with $25 \mathrm{rpm}$ for four minutes, which means 100 rotations. The friability of tablets is expressed in percentage [12]:

$$
\text { Friability, } \%=\frac{\text { initial weight }- \text { final weight }}{\text { initial weight }} \times 100 \text {. }
$$

2.2.5. Statistical Analysis. D-optimal mixture design was used to determine the optimum amount of ingredients used in okara tablet formulation toward the responses, which are hardness and friability of the tablet. The statistical parameters used in evaluating and selecting the best-fitted model are coefficient of determination $\left(R^{2}\right)$, adjusted coefficient of determination (adjusted $R^{2}$ ), predicted coefficient of determination (predicted $R^{2}$ ), coefficient of variation (C.V.), standard deviation, predicted residual sum of squares (PRESS), lack-of-fit, and regression data ( $p$ value and $F$ value). The statistical analysis also constructs an equation from the best-fitted model. From the equation, the positivity of the coefficient presents the positive contribution toward the response, and vice versa. Also, a contour plot and threedimensional response surface graph for each response were generated by Design-Expert Software Version 7.0 for a better explanation.

\section{Results}

3.1. Screening the Range of Variables. Okara, maltodextrin, Avicel PH-101, and guar gum were chosen to be the variables toward the responses: hardness and friability. The levels of okara (25-50\% w/w), maltodextrin (5-15\% w/w), Avicel PH$101(18-68 \% \mathrm{w} / \mathrm{w})$, and guar gum $(0-20 \% \mathrm{w} / \mathrm{w})$ were selected (Table 1).

3.2. Hardness and Friability of Okara Tablets. Table 2 shows that there are 20 formulations in this physical tests analysis. The actual and predicted data sets of the physical tests were tabulated in Table 3.

3.2.1. Effect of Variables to the Hardness of Tablets. Figures 1 and 2 show the relationship between the hardness of a tablet and the deployed component variables (percentage of okara, maltodextrin, guar gum, and Avicel PH-101). The statistical analysis from Design-Expert Version 7.0 software suggested a linear model as the best model with $p<0.0001$. The model is significant and the lack-of-fit is insignificant (Table 4). This means that the possibility of error occurring is low. 


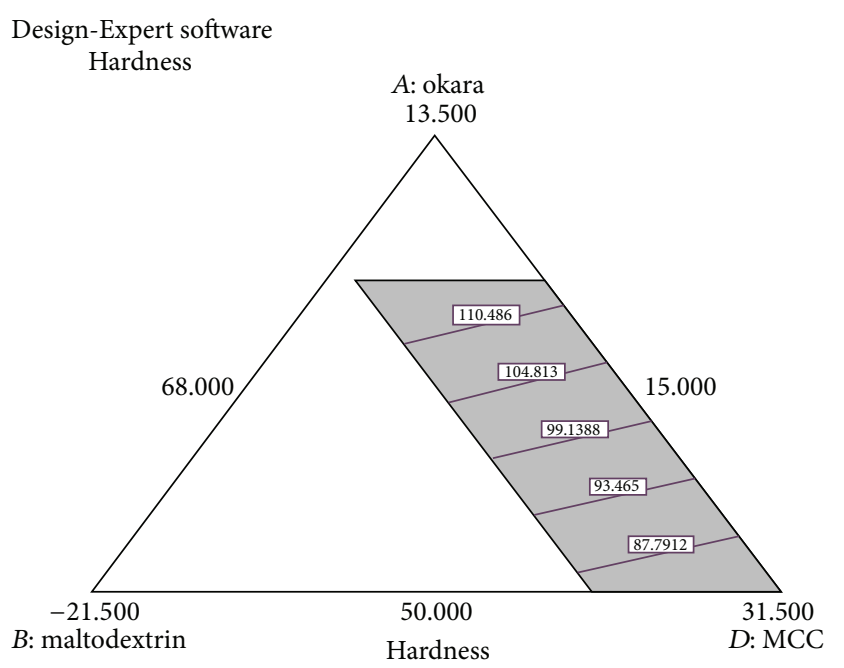

$$
\begin{array}{llrl}
X 1 & =A: \text { okara } & & \text { Actual component } \\
X 2 & =B: \text { maltodextrin } & & C: \text { guar gum }=1.500 \\
X 3 & =D: \text { MCC } & &
\end{array}
$$

FIGURE 1: Contour diagram of relationship between three variables, $(A)$ percentage of okara, $(B)$ percentage of maltodextrin, and $(D)$ percentage of Avicel $\mathrm{PH}-101$, and with actual component of guar gum $(C=1.50 \%)$ to the hardness of the tablet.

Final equation for hardness of okara tablet is

$$
\text { Hardness, } \begin{aligned}
Y_{1}= & 0.33327 A+1.18672 B-1.14021 C \\
& +1.56709 D .
\end{aligned}
$$

3.2.2. Effect of Variables on the Friability of Tablets. Figures 3 and 4 show the relationship between the percentage of component variables and the friability of the tablet. The statistical analysis suggested a Log10 linear model with $p<0.0001$. The model was significant and lack-of-fit was insignificant, which means the model demonstrates the goodness of fit (Table 4).

Final equation for friability of okara tablet is

$$
\begin{aligned}
\log 10(\text { Friability }), Y_{2}= & 0.004255 A+0.0047081 B \\
& +0.013067 C-0.0016455 D .
\end{aligned}
$$

3.3. Optimization Using D-Optimal Mixture Design. DesignExpert software generates 20 formulations to produce optimized okara tablet with acceptable hardness and friability. The optimum percentages of ingredients selected were as follows: okara $47.0 \%$, maltodextrin $14.0 \%$, guar gum $2.0 \%$, and Avicel PH-10135.0\%. The recommended formulation was carried out and the actual values and predicted values of okara tablet hardness and percentage of friability were compared (Table 5).

\section{Discussion}

4.1. Screening of Variables. Preliminary studies were carried out to screen out the suitable variables for the responses
TABLE 4: Data from analysis of variance (ANOVA) for hardness and friability of okara tablet.

\begin{tabular}{lcc}
\hline & Hardness & Friability \\
\hline Model & Significant & Significant \\
$R^{2}$ & 0.9893 & 0.9103 \\
Adjusted $R^{2}$ & 0.9866 & 0.8911 \\
Predicted $R^{2}$ & 0.9810 & 0.8635 \\
$p$ value & 0.1243 & 0.1047 \\
$F$ value & 2.97 & 3.23 \\
C.V. \% & 3.64 & 19.96 \\
Lack-of-fit & Not significant & Not significant \\
Standard deviation & 3.020 & 0.046 \\
PRESS & 193.390 & 0.044 \\
\hline
\end{tabular}

Note: $p<0.05$ is significant.

$p>0.05$ is not significant.

and to select the ranges of variables in the okara tablet formulation. Initially, the excipients used in the okara tablet formulation were studied. Maltodextrin is selected as the binder, Avicel PH-101 was chosen as the filler, the guar gum was chosen as disintegrant, also, okara additionally tested as variables to study its impact toward reactions. For safety, the hardness should be more than $40 \mathrm{kN}$ and the friability should be less than $2 \%$ [13]. The hardness and friability fall in the accepted ranges when the level of okara $(25-50 \% \mathrm{w} / \mathrm{w})$, maltodextrin (5-15\% w/w), Avicel PH-101 (18-68\% w/w), and guar gum $(0-2 \% \mathrm{w} / \mathrm{w})$.

\subsection{Hardness and Friability of Okara Tablets}

4.2.1. Effect of Variables on the Hardness of Tablets. Figures 1 and 2 and (3) from hardness test show that a high Avicel PH-101 percentage gives the highest hardness because Avicel PH-101 is known as a filler-binder in tablets [14]. During compression, Avicel $\mathrm{PH}-101$ which is made of fiber particles may undergo a process called fragmentation, which means the breakage of particles into the smaller units. The fragmentation process increases secondary binding points; consequently, tablet hardness gets stronger [15]. Avicel PH-101 also improves the flowability, compactibility, and compressibility of the tablets $[15,16]$. The most important characteristic that the tablet filler should have is the compactibility. Strong tablets are made with densely compacted powder. Avicel PH101 has the smallest particle size among other components, which is $50 \mu \mathrm{m}$. Therefore, a smaller powder particle size will be more compactible compared to a larger powder particle size [17]. In addition, increasing the amount of maltodextrin increases the hardness of the tablet. Final equation for hardness of okara tablet and Figures 1 and 2 did prove that increasing the percentage of maltodextrin affects the hardness of an okara tablet. Maltodextrin, which is usually used as binder in tableting, has also a large effect on the hardness of the tablet. Maltodextrin can absorb and desorb moisture easily from the humidity due to its natural behavior as an amorphous sugar [18]. That explains how the binder provides cohesiveness within the powders in tablet formulation [19]. 
TABle 5: Predicted and actual values of hardness and percentage of friability of optimal formulation.

\begin{tabular}{lcccccccc}
\hline & Independent variables & & Hardness & \multicolumn{3}{c}{ Friability } \\
$A$ & $B$ & $C$ & $D$ & Actual & Predicted & RSE & Actual & $\begin{array}{c}\text { Predicted } \\
\text { value }\end{array}$ \\
$(\%)$ & $(\%)$ & $(\%)$ & $(\%)$ & value & value & $(\%)$ & value & $(\%)$ \\
\hline 47 & 14 & 2 & 35 & 84.922 & 84.845 & 0.0908 & 1.697 & 1.714 \\
\hline
\end{tabular}

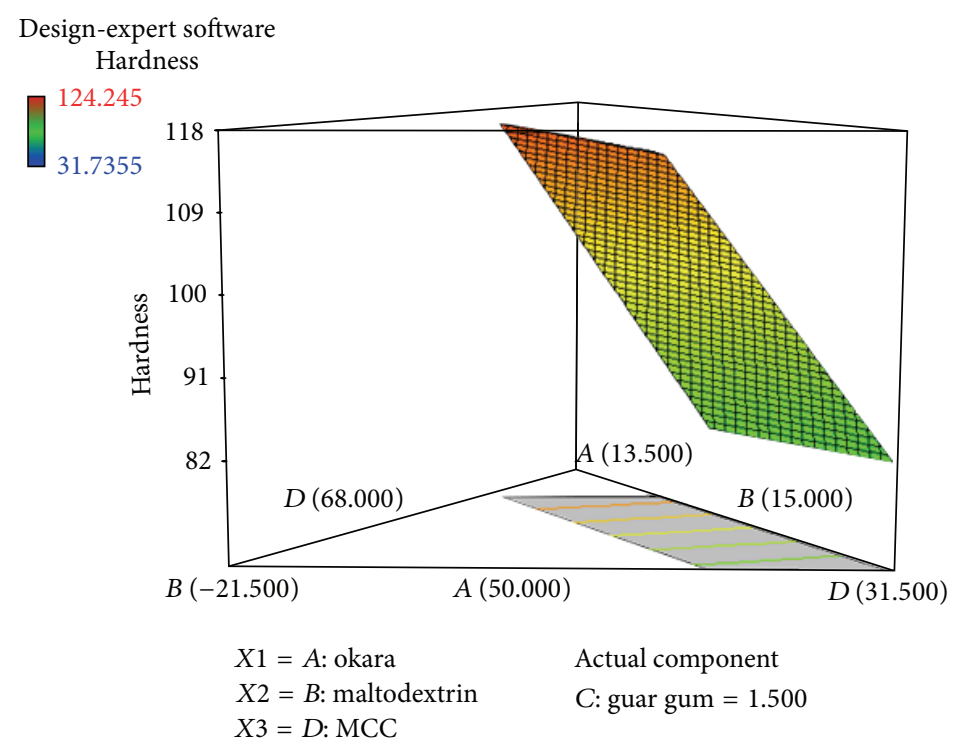

FIGURE 2: 3D diagram of relationship between three variables, $(A)$ percentage of okara, $(B)$ percentage of maltodextrin, and $(D)$ percentage of Avicel PH-101, and with actual component of guar gum $(C=1.50 \%)$ to the hardness of the tablet.

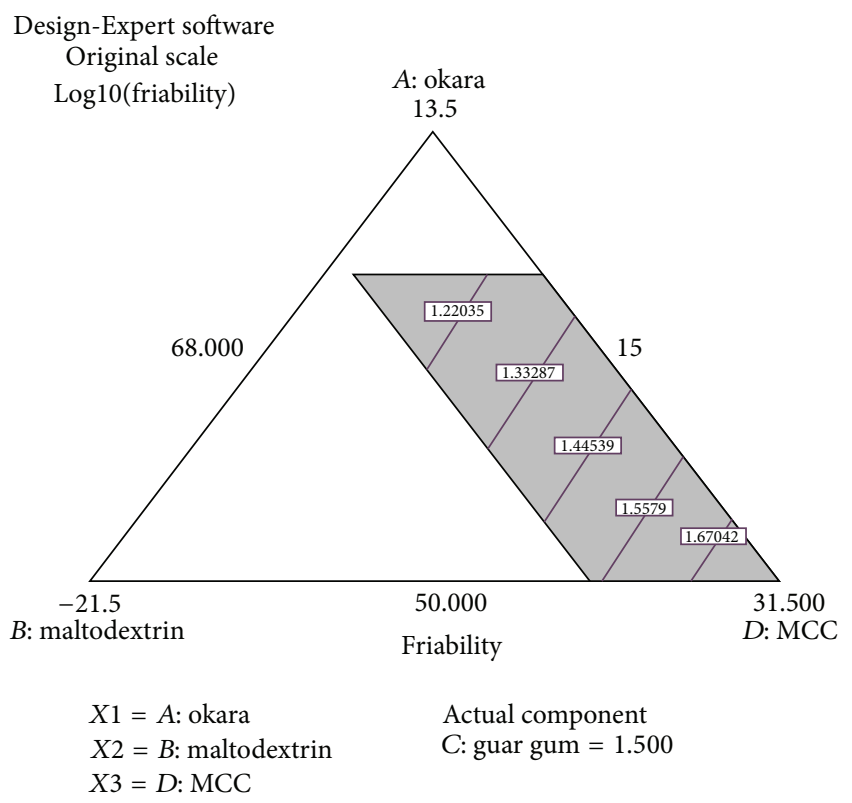

FIgURE 3: Contour diagram of relationship between three variables, $(A)$ percentage of okara, $(B)$ percentage of maltodextrin, and $(D)$ percentage of Avicel $\mathrm{PH}-101$, and with actual component of guar gum $(C=1.50 \%)$ to the friability of the tablet.

The composition of okara just slightly affects the hardness of the tablet and guar gum had a negative effect on hardness which is shown in (3). The main component of okara is fiber; hence, a larger percentage of okara can also exhibit greater hardness of the tablet. In conclusion, the hardness of the tablet is affected by the behavior of the powder. Thus, in the tablet formulation, Avicel PH-101 had the highest effect on tablet hardness due to its compactibility.

4.2.2. Effect of Variables on the Friability of Tablets. Linear regression model of friability test generated adequate model with coefficient of determination $\left(R^{2}=0.8807\right)$, but it can be improved. Sometimes due to inhomogeneity of variance and abnormality of errors in the model, transformation of model is an effective method to improve the ANOVA of friability test [20]. The Box-Cox plot from Design-Expert recommends natural $\log$ transformation $(\lambda=0)$ of the model. The advantages of model transformation are to stabilize the variance of residual and normalize the distribution of the residual. The final coefficient of determination $\left(R^{2}=0.9103\right)$ is greater than the previous one. This result shows that the error has been corrected during the transformation. Figures 3 and 4 and (4) for friability test show that the Avicel PH-101 had a positive effect on the percentage of friability. Increasing the percentage of Avicel PH-101 in the tablets decreases the percentage of friability. According to Bastos et al. [21], microcrystalline cellulose improves both crushing strength and percentage of friability [21]. Segale et al. [22] reported that a fast melting tablet (FMT) containing Avicel PH-101 exhibits low friability compared to maltodextrin. FMT containing maltodextrin is weaker than FMT containing Avicel PH-101 [22]. The final equation of friability also showed that maltodextrin 


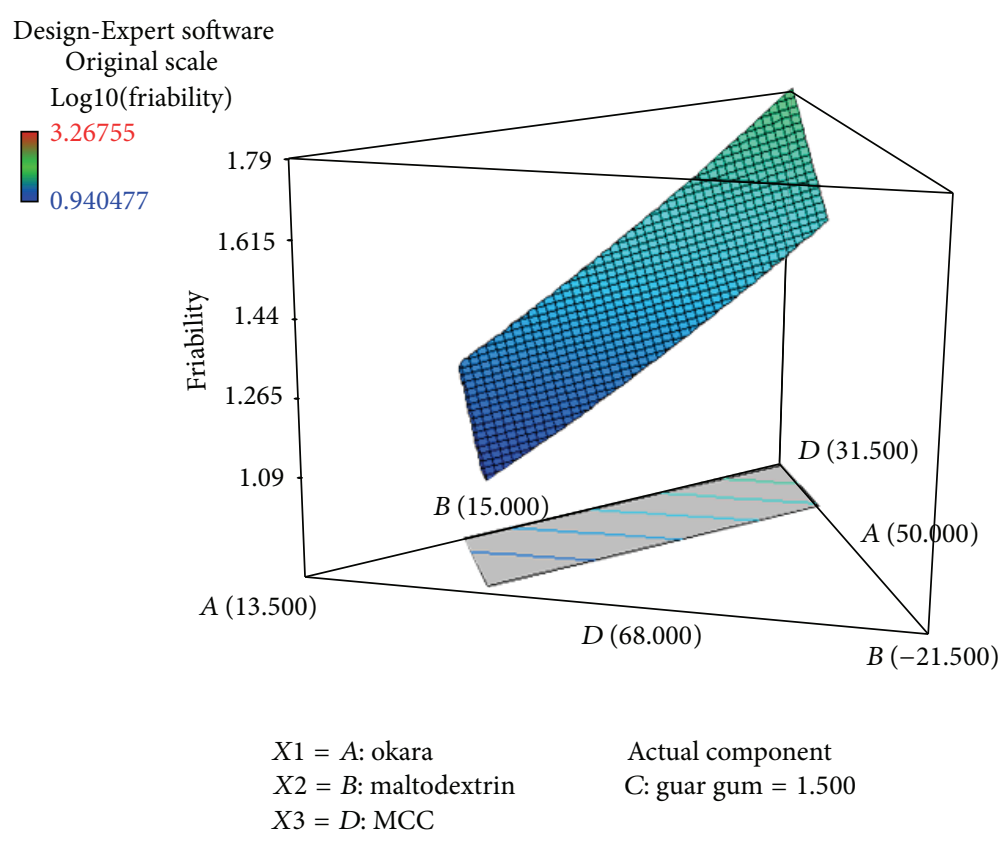

FiguRE 4: 3D diagram of relationship between three variables, $(A)$ percentage of okara, $(B)$ percentage of maltodextrin, and $(D)$ percentage of Avicel PH-101, and with actual component of guar gum $(C=1.50 \%)$ to the friability of the tablet.

does have an effect on the percentage of friability. Also, okara has a slightly negative effect on maintaining tablet hardness. Guar gum is not suitable to be a tablet binder since increasing guar gum makes the tablet more friable. Thus, the percentage of guar gum should be low to ensure the good physical quality of tablets. Therefore, a high percentage of Avicel PH-101 in tablet formulation can keep the tablet from breaking easily.

4.3. Verification of the Model. In order to verify the optimum formulation generated from the Design-Expert software, verification of data is needed. The results were verified by relative standard error (RSE):

$$
\text { RSE, } \%=\frac{\text { Actual value }- \text { Predicted value }}{\text { Predicted value }} \times 100 \text {. }
$$

The optimized formulation of okara tablet (Table 5) showed nonsignificant difference between the predicted values and actual values for both hardness and percentage of friability of tablet. Therefore, the finalized equation for hardness and percentage of friability generated by Design-Expert 7.0 software is acceptable to be used in okara tablet formulation.

\section{Conclusion}

Hardness of the tablets cannot be evaluated by individual usage of the crushing strength test; but the friability test is also necessary. Avicel PH-101 showed a positive effect for both physical tests: hardness and friability. Therefore, the percentage of Avicel PH-101 should be large to make the tablet stronger. The percentage of maltodextrin can be at the medium level. The percentage of okara as the principle ingredient ought to be as high as not influencing the physical properties. They had a positive effect on tablet hardness, but not on the percentage of friability. Guar gum has no positive effect on both physical tests but is needed as the disintegrant of the tablet. Therefore, it is limited to a low amount of tablet formulation.

\section{Conflict of Interests}

All authors declare that they have no conflict of interests.

\section{Acknowledgment}

The authors gratefully acknowledge the financial support from Graduate Research Fellowship (GRF) grant under Universiti Putra Malaysia.

\section{References}

[1] B. Li, M. Qiao, and F. Lu, "Composition, nutrition, and utilization of okara (soybean residue)," Food Reviews International, vol. 28, no. 3, pp. 231-252, 2012.

[2] S. Bowles and I. M. Demiate, "Physicochemical characterization of the soymilk by product-okara," Ciência E Tecnologia de Alimentos, vol. 26, no. 3, pp. 652-659, 2006.

[3] E. N. Whitney and S. R. Rolfes, Understanding Nutrition, Cengage Learning, Belmont, Calif, USA, 2008.

[4] R. H. Eckel, Obesity: Mechanisms and Clinical Management, Lippincott Williams \& Wilkins, Philadelphia, Pa, USA, 2003.

[5] H. Wen and K. Park, Oral Controlled Release Formulation Design and Drug Delivery: Theory to Practice, John Wiley \& Sons, Hoboken, NJ, USA, 2011. 
[6] S. C. Gad, Pharmaceutical Manufacturing Handbook: Production and 199 Processes, John Wiley \& Sons, Hoboken, NJ, USA, 2008.

[7] J. A. Seitz and G. M. Flessland, "Evaluation of the physical properties of compressed tablets. I. Tablet hardness and friability," Journal of Pharmaceutical Sciences, vol. 54, no. 9, pp. 1353-1357, 1965.

[8] L. Eriksson, Design of Experiments: Principles and Applications, MKS Umetrics AB, Malmö, Sweden, 2008.

[9] R. G. Brereton, Chemometrics: Data Analysis for the Laboratory and Chemical Plant, John Wiley \& Sons, West Sussex, UK, 2003.

[10] K. H. Esbensen, D. Guyot, F. Westad, and L. P. Houmoller, "Multivariate data analysis," in Practice: An Introduction to Multivariate Data Analysis and Experimental Design, Aalborg University, Esbjerg, Denmark, 2002.

[11] K. Valko, Separation Methods in Drug Synthesis and Purification, Elsevier, Amsterdam, The Netherlands, 2000.

[12] Stationery Office, British Pharmacopoeia 2012, Stationery Office, London, UK, 2011.

[13] A. K. Mitra, C. Mitra, D. Kwatra, and A. D. Vadlapudi, Drug Delivery, Jones \& Bartlett Publishers, Burlington, Mass, USA, 2014.

[14] S. Michelson and T. Schofield, The Biostatistics Cookbook: The Most User-Friendly Guide for the Bio/Medical Scientist, Kluwer Academic Publishers, Dordrecht, The Netherlands, 1996.

[15] G. Shlieout, K. Arnold, and G. Müller, "Powder and mechanical properties of microcrystalline cellulose with different degrees of polymerization," AAPS PharmSciTech, vol. 3, no. 2, pp. 45-54, 2002.

[16] G. Thoorens, F. Krier, B. Leclercq, B. Carlin, and B. Evrard, "Microcrystalline cellulose, a direct compression binder in a quality by design environment-a review," International Journal of Pharmaceutics, vol. 473, no. 1-2, pp. 64-72, 2014.

[17] E. Lahdenpää, M. Niskanen, and J. Yliruusi, "Crushing strength, disintegration time and weight variation of tablets compressed from three Avicel PH grades and their mixtures," European Journal of Pharmaceutics and Biopharmaceutics, vol. 43, no. 3, pp. 315-322, 1997.

[18] Y. S. R. Elnaggar, M. A. El-Massik, O. Y. Abdallah, and A. E. R. Ebian, "Maltodextrin: a novel excipient used in sugar-based orally disintegrating tablets and phase transition process," AAPS PharmSciTech, vol. 11, no. 2, pp. 645-651, 2010.

[19] P. Shailendra, "Natural binding agents in tablet formulation," International Journal of Pharmaceutical \& Biological Archive, vol. 3, no. 3, pp. 466-473, 2012.

[20] W. F. Smith, Experimental Design for Formulation, vol. 15 of ASA-SIAM Series on Statistics and Applied Probability, SIAM, Philadelphia, Pa, USA, 2005.

[21] M. D. O. Bastos, R. B. Friedrich, and R. C. R. Beck, "Effects of filler-binders and lubricants on physicochemical properties of tablets obtained by direct compression: a 22 factorial design," Latin American Journal of Pharmacy, vol. 27, no. 4, pp. 578-583, 2008.

[22] L. Segale, L. Maggi, S. Conti et al., "Preformulation study of fast melting tablets," in Proceedings of the 5th World Meeting Pharmaceutics, Biopharmaceutics and Pharmaceutical Technology, Geneva, Switzerland, March 2006. 

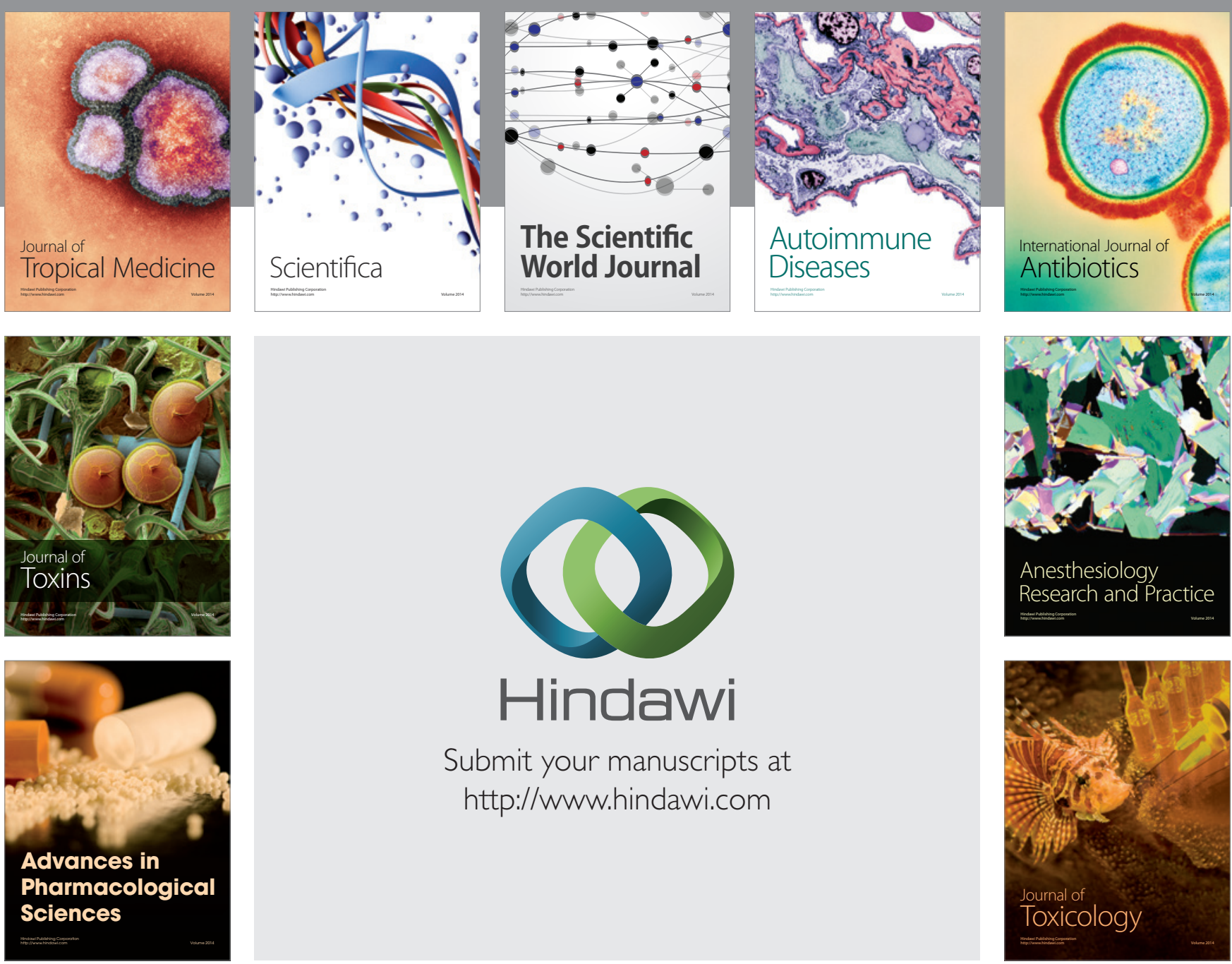

\section{Hindawi}

Submit your manuscripts at

http://www.hindawi.com
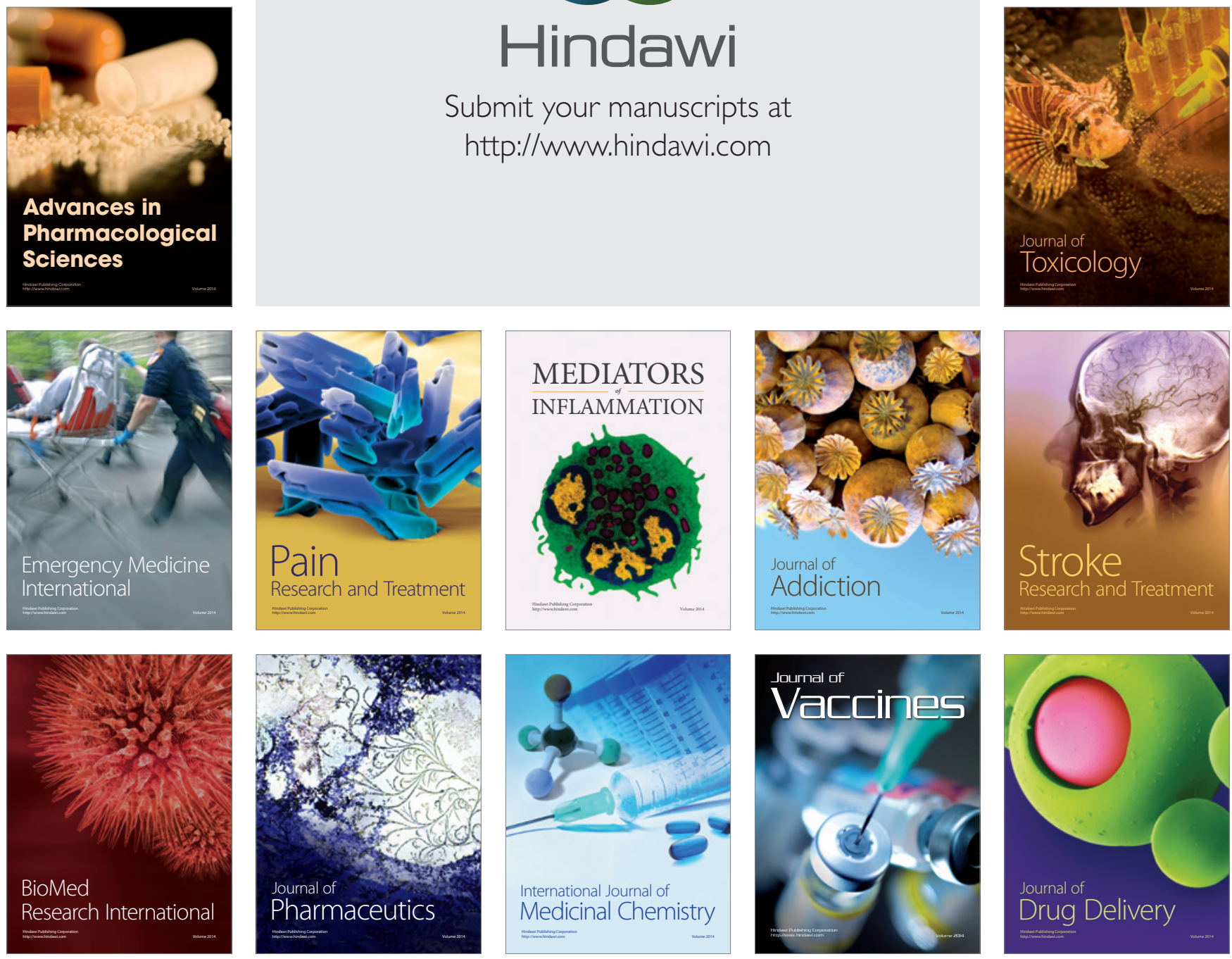